\title{
Introduction: thought, law, rights and action in an age of environmental crisis - in search of better future histories*
}

\section{Anna Grear and Evadne Grant}

The original GNHRE Oñati International Workshop 2012 - by which this edited collection is inspired, from which it draws and to which it adds was set up in full knowledge that the relationship between 'human rights' and 'the environment' (both as constructed (legal) domains) remains both complex and fractious.

At the institutional level these two domains (even taken as unproblematic referents to commonly understood concerns) still have an uneasy connection notwithstanding increasing evidence of their interconnections, while at the philosophical level it has often been asserted that the individualism of human rights makes them inherently ill-suited, as a moral and juridical category, to address the inherently more collective and less 'anthropocentric' - concerns of environmentalism.

Human rights and environmental law are also unevenly theorised. Human rights scholarship is richly reflexive, manifesting an intense, sustained and energetic degree of contestation and theoretical disputation. It is multi-faceted and multi-perspectival: its traditional accounts and

* This edited collection was inspired by a series of articles resulting from a workshop, 'Human Rights and the Environment: In Search of a New Relationship', held at the International Institute for the Sociology of Law, Oñati, Spain, 14-15 June 2012 and coordinated by Anna Grear (Cardiff University). The editors of this collection would like to thank Karen Morrow, Louis Kotze and Andreas Philippopoulos-Mihalopoulos for their comments on an earlier version of this introductory chapter - and to thank, in particular, Lorraine Code for her close, analytical engagement with that earlier version; the anonymous reviewers for the Oñati Socio-Legal Series and Sol Picciotto, Cristina Ruiz and Angela Melville for their comments on and support for the original articles by which this collection was inspired. 
assumptions are routinely interrogated by critical, subaltern legal scholarship. Meanwhile, despite a growing interest in critiquing so-called 'anthropocentric' perspectives, environmental law remains largely Eurocentric, dominated - in the main - by Western cultural assumptions and practices of law and governance - while much environmental law scholarship focuses primarily upon on a wide range of legal and regulatory responses to environmental pressures.

The multi-layered complexity of the relationships between human rights and environmental law; between human rights and environmentalism and between humanity and the living order suggests the need to explore the dynamics between philosophy (including jurisprudence), legal doctrine and structures, and the more fluid realms of the socioecological, reflected by, among other things, community-led praxis.

The workshop, Human Rights and the Environment: In Search of a New Relationship, sought to bring together a group of scholars, lawyers, policy analysts and others to work together - through wide-ranging, careful and at times uncomfortable conversation - on re-imagining the relationship between human rights and the environment. The framework of the event was explicitly designed to move from philosophical foundations, through consideration of current legal responses and frameworks, and onwards to embrace experience-led insights emerging from embedded social activism and NGO engagements. This edited collection broadly traces the organisational structure of the 2012 workshop, focusing on four themes: 1 Philosophical Investigations; 2 Reconfiguring the Legal; 3 Activism and Praxis and 4 Multi-level Reformulations.

\section{PART 1: PHILOSOPHICAL INVESTIGATIONS}

This section of the collection opens with Lorraine Code's critical reflection upon structures of mastery and their political resilience revealed by practices of epistemic domination in the context of the climate-change debate. Code addresses the theme of 'Doubt and Denial: Epistemic Responsibility Meets Climate Change Scepticism' with the purpose of making the interconnections between three nodes of epistemic engagement legible. She characterises these nodes as being, first, the fraught and politically freighted rift between ecologists and climatechange sceptics; secondly, issues concerning the evaluation of testimony as indicators of questions concerning subjectivity, agency and freedom and in particular, the impossibility of the abstract, 'un-located' autonomous gender-neutral subject of Western epistemology; and finally, the 'ongoing ad feminam treatment [of Rachel Carson's work by] the science 
sceptics'. This third node of engagement, for Code, presents a nexus in which the first two converge and are exposed (through her examination of Carson's treatment) as being sites of the operationalisation of sexedgendered specificities constructing the epistemic 'authority' of (male) subjects smuggled within and behind the structure of the generic 'objective' epistemic subject of Western mastery. Deploying a single text, Merchants of Doubt by Naomi Oreskes and Erik M Conway, Code notes the way in which a false neutrality operates to sustain climate doubt and ignorance in the predominantly white, Western world and to excise the fact that 'specifically situated, and not disinterested, human subjects' produce a 'science' dedicated to climate-change scepticism. This 'science' is committed to the notion - fundamental to the epistemic operationalisation of climate denial - of the homogenous human subject: a bland construction perfectly fitting the screen of 'objectivity' designed to foreclose critique and/or resistance. Code argues that the growing significance of testimony in social epistemology creates spaces for engagement with questions concerning the accepted division of intellectual-epistemic labour in Western societies. This also provides the opportunity to interrogate the related construction of the epistemic power 'to know'.

What Code exposes is, in effect, a politics of disguised epistemic location. She urges a conscious and resistive divergence from the 'neutral', individualistic mode of knowledge production towards a communal one that openly acknowledges the limits of our knowing. Relatedly, she argues for acknowledgment of the "need for critical analysis of some of the taken-for-granted assumptions about subjectivity that prevail in epistemic communities, and for ascertaining the place of those communities in constructing and circulating public knowledge'. Thus, Code brings the politics of subjectivity into full view, arguing that subjectivities elevated as 'either positive epistemic exemplars or as the reverse' should be subjected to genealogical scrutiny - to examination, in short, of exactly how, and why, the epistemic status of such subjects is given or withheld.

Code's analysis is decidedly feminist. It attacks epistemic mastery by exposing it as an exercise of power. She deliberately characterises situated advocacy as being a feminised practice engaging the adversarial, legalistic (and masculinist) construction of 'authoritative' scientific and legal knowledge. If knowledge is power (the relation implicit in epistemic mastery) then the epistemically responsible, critical, unmasking of 'neutral' knowledge is a thoroughly necessary - and highly political act. Code invites us, in effect, into a struggle for epistemic justice. 
Philippopoulos-Mihalopoulos, while sharing some common ground with Code, moves beyond Code's immediate concern with questions of epistemological mastery (though doubtless he would agree with her critique) to seek out new ontological foundations for a 'critical environmental law' lying beyond, as he would see it, the contemporary fixation with epistemological questions in the place of ontological ones. Addressing the theme of 'Actors or Spectators? Vulnerability and Critical Environmental Law', Philippopoulos-Mihalopoulos seeks to explore what it might mean to embrace our 'thrown-ness' (Heidegger's phrase) into a new, category-confounding, vulnerability-exposing open ontology. Philippopoulos-Mihalpoulos argues that the reified ontological polarisation between humans and the 'environment' has been replaced, of late, by an epistemological debate between anthropocentricity and ecocentricity. This is a move that he regards as problematic in two key respects. First, it distances us from the ontology of the human/non-human interaction and, in this sense, replaces 'ontology with an epistemology of supposed action'. Secondly, the move legitimates, in his view, the 'perennial problem ... of "the centre" (a point having considerable political resonance with Code's critique of the dominance of the Western epistemic subject).

For Philippopoulos-Mihalopoulos, the move from ontology is a form of avoidance - a move as he puts it, avoiding exposure to the vulnerability of being in the wild and dizzying space of the 'middle' rather than in the comforting dominance of the epistemic 'centre'. PhilippopoulosMihalopoulos invites his readers to re-experience their true ontological location: as beings exposed, thrown-in, 'abandoned' to the forces of a-centricity that characterise the true complexities and energies of existence. There is a need, he argues, for semantics that 'move away from the glib safety of the centre and [its] consequent, misaddressed dialectics [arguing that][a n]ew semantics ... must be sought on a surface of acentric continuum, traversed by velocities and pauses that do not easily subscribe to centralising generalisations'. In short, this is an invitation to give up epistemic power and privilege. It complements Code's emphasis upon the exposure and resistance to the central epistemic subject's power of 'knowing' - but moves us into a multi-planar dislocation of the 'human' viewpoint.

Philippopoulos-Mihalopoulos follows Deleuze and Guattari onto the 'the plane of immanence' - inviting a fall, as PhilippopoulosMihalopoulos puts it, into the 'all-embracing sum of folds and falls and connections that contains its own origin, causality and teleology without transcendence'. Ontology and epistemology retain no clearly demarcated binary relationship, for Philippopoulos-Mihalopoulos argues that the 
plane of immanence 'operates on both an epistemological and an ontological level', allowing no division between the observing spectator and the involved actor, no distinction along the lines of human/natural/ artificial/technological - for all these 'fold into each other and constantly emerge as epistemological and ontological hybrids'.

Key to Philippopoulos-Mihalopoulos's argument is the embrace of vulnerability. Vulnerability breaks with the need for any observational distance: vulnerability radically undermines the impossible neutrality that Code's paper so vigorously attacks. Vulnerability is full exposure to the 'space of the middle': '[t]here is no screen to hide behind, no distance afforded by epistemology, no negotiating moments of discourse. The surface is pure ontology, inescapably filled with a brutality of continuous, uninterrupted presence'. This is a vulnerability that invites - in a Heideggerian mode - a full exposure to ontological 'thrownness' in the world.

What might the implications for law be? Philippopoulos-Mihalopoulos offers his readers an account of a critical environmental law that opens out the paradoxical nature of environmental law itself as that field of law potentially most open, most vulnerable, to 'non-legal' inputs and yet simultaneously in need of its own juridical identification and partial closure.

Addressing a related challenge, Margherita Pieraccini examines two representations of the legal relationship between human rights and environmental regulation, also drawing on the work of Heidegger - this time to present alternative foundations. Pieraccini divides her discussion into a reflexive duality: the first part of her chapter is dedicated to an examination of 'the oppositional view' that 'corresponds' to what she calls 'the initial phase of the relationship between human rights and public environmental regulation'. This by necessary implication focuses on a profound subject-object division between human rights and 'the environment'. In law, this is expressed as on the one hand, a subjective rights-based approach circling around a human subject and on the other hand, the 'external, state regulation' of a 'de-subjectivised good: the natural environment'. For Pieraccini, the assumption lying at the basis of this view is the Cartesian-Kantian subject-object split. However, the Kantian subject-object split, in particular, especially because of the influence of the Kantian moral and legal subject on human rights law, invites a direct critical engagement with the topic of epistemic mastery as it has been worked out through law: the Kantian subject-object duality, Pieraccini suggests, 'positions human rights and environmental regulation in two bounded and conflictual legal realms'. 
Pieraccini's response to this is to analyse what she calls the 'interactive view'. This approach, her argument implies, is increasingly discernible in contemporary legal and policy developments and in academic scholarship. She argues that there is a 'greening' of human rights law and a related 'righting' (as she puts it in verb form) of environmental law. This dual movement reshapes, Pieraccini suggests, the boundaries and connections between the two fields. The weakness, however, of the interactive view is that it is an empiricist, policy-dominated phenomenon in need of a more radical critical engagement with traditional ontological assumptions. The gap between 'human subjects' and 'the environment' - the subject-object dichotomy lying behind, as Code would insist, the epistemology of mastery - remains intact.

Pieraccini is interested in exploring how the abandonment of Cartesian-Kantian dualism and a 'focus on the question of the meaning of Being' enables relational thinking. For an ontological account capable of producing such a renewing imaginary, she turns, naturally enough perhaps, to Heidegger.

Heidegger, she suggests, was the first philosopher to re-open 'the problem of Being as distinguished from beings'. A Heideggerian account suggests that 'the two separate legal spheres of human rights and environmental regulation are parts of, and constituent of, a particular way of revealing Being that conceals practices of dwelling and ethics of care'. There is thus a need to move beyond existing concepts to open up spaces where a 'poietic' (in the Heideggarian sense of 'bringing forth') view of law can be disclosed. This argument, as will become clear later, has considerable resonance with the phenomenology of the commons-based dynamics discussed by Burns Weston and David Bollier in their chapter in this collection.

Code, Philippopoulos-Mihalopoulos and Pieraccini share some fundamental concerns and philosophical intuitions, for all the nuanced differences in their accounts. The selves that emerge from their accounts, taken together, are situated selves - not omniscient or radically separate from 'nature', but nodes of emergence within a systemically complex, vulnerable and contingent set of interwoven actualities. Code's responsibilised epistemic subject is humble - self aware as to the politics of location and positioned in tension with the epistemic subject assuming the centrality of mastery. Philippopoulos-Mihalopoulos 'throws' an epistemically limited subject into a radical, open ontology in which easily assumed distinctions simply break down and for which the exposed vulnerability of the middle is the antithesis of 'the centre'. Pieracinni, while she retains more ontological duality in her understanding than Philippopoulos-Mihalopoulos, invites a new sense of situtatedness in 
which law itself, as a poeitic dynamic, might emerge into new, interwoven relationalities transcending traditional dyadic structures.

In 'Radicalism and Conservativism in Environmental Law', Coyle argues from a natural law position that re-inscribes precisely the kind of human uniqueness that Philippopoulos-Mihalopoulos, at least, would be keen to cast aside - a uniqueness, for Coyle, hinging on the nature of the human being 'as a rational animal'. Indeed, Coyle argues that what Western philosophical accounts have in common is the central idea of the human being as being 'in certain respects, apart from nature' - and that for him - this 'apartness' has no intrinsic sense of 'aboveness' or of superiority. It is, however, central to ethical understanding.

For Coyle, 'the separation of Mankind from the rest of nature is ... as important as its situation within a wider order of nature', and hinges on the human facility for language - a facility that means that 'for human beings ... there is not "the world" and then "an interpretation" of it ... there is no separation between our experience of the world and the meaning we give to it'. The implication of this is that 'there exists no platform from which we are able to abandon a "human" view of the world and adopt a perspective from which human concerns, interests and structures of meaning and understanding are not central'. Accordingly, radical ecological and postmodern viewpoints that insist on taking the 'standpoint of the other' mistakenly over-stretch a human capacity for something more like a standpoint empathy:

Radical 'ecocentric' thought began from the assumption that environmental concerns must be derived from an ethical standpoint that requires us to give up a distinctly human perspective. Such a standpoint is not available. What in fact is required is a standpoint from which ethics does not terminate in human concerns, but is properly transcendent of them.

This 'proper' transcendence is found in systems of thought (such as natural law, Christianity, Daoism, Confucianism) that yield an environmental ethic that separates intrinsic environmental value from human concerns and purposes - a task not assisted by the assumption of an ecologically radical standpoint assuming an impossible epistemic transcendence. In this insistence, at least, Coyle's account echoes that of Code, Philippopoulos-Mihalopoulos and Pieraccini - each of whom, from very different philosophical starting points, insist upon epistemic situatedness and an accompanying form of epistemic humility very far removed from a transcendence of 'humanity'.

Coyle's central concern is to trace out the tensions between what he calls 'anti-conservative' 'radical' aspects of environmental legal thought 
and the deeper, 'conservative' (conserving) ideas of environmental law (and human rights). Law, he argues, functions as that which reflects and protects bonds uniting society, and modern environmental principles draw upon the deepest aspects of property law and tort as mechanisms of careful social-interest balancing. Such conserving aspects of legal relations are abandoned at the risk of distorting the legal order such that it becomes a mere 'system of adventitious adjudication between competing instrumentalities'.

For Coyle, environmental legal radicalism - such as that emerging from feminist, eco-feminist, Marxist and other critical positions - reflects 'anti-conservative forces within politics which, rather than seeking the deeper integration of a form of social life, go off in search of an ideal re-ordering of society; a re-ordering which is nevertheless understood in so many different and non-compossible ways'. Into this tension, Coyle inserts the contribution of human rights - which despite the fact that they, like environmental law, reflect conservative and anti-conservative elements - offer a more direct mode of expression for conservative (in Coyle's intended sense) ideas. This is because human rights point towards the important fact that "certain common conditions are required if [human beings] are to flourish in this world, and that such flourishing can therefore be achieved or promoted only as a common endeavour ... A clean and habitable environment is certainly one of these commonalities'. Crucially, however, this commonality emerges from a richer understanding of society than is dominant in the modern liberal democratic state, in which humans are 'consumers' competing to achieve diverse individualistic goals. For Coyle:

the doctrine of human rights promises, though no more than partially, to return us to something closer to the pre-modern conception of the person: as a being with a unique and individual soul, for which he alone is responsible, but which is embodied in a fleshly home whose essential characteristics and problems, and whose ultimate well-being, are inexorably linked with others of his kind. Human rights emphasize the collective context in which human life runs its course. In so doing, they may perhaps produce a more integrated understanding of law; and of rights that are ultimately tempered by the needs of a common environment.

Albeit by a radically different route, Coyle returns us to the ethical intimations of materiality, embeddedness and situatedness. However, this emphatically does not reflect the immanent open ontology of Philippopoulos-Mihalopoulos, nor that implied by the ecological epistemological project of Code. Nor is it Heideggarian. Coyle's account reflects an ontology of the human self as a duality of body and soul - a 
being not completely immanent - albeit that this human's fallibility of perspective, embodied limitation, social situatedness importantly underlines a human incapacity to escape the limitations of human perspective itself.

What emerges from the convergence of all four of these chapters is a productive provocation to tease out some related and challenging puzzles. What standpoint positions are even possible? What kinds of epistemic empathy and feats of ontological imagination open up future histories that simultaneously exceed and engage critically with the practices and patterns of power so central to the destruction driving our climate crisis and related ecological crises? What concept of 'nature' (if any) might be liberatory - or oppressive - and for what/whom? Hidden within all these questions, moreover, is the substrate that Code's work relentlessly forces us to confront - the central question of the political and epistemic constitution of forms of subjectivity - and the forms and processes of their construction and dismantling: Who and what - and how - is privileged by the way we construct our philosophical, juridical, political, scientific, social, economic and ecological imaginaries?

\section{PART 2: RECONFIGURING THE LEGAL}

We turn now to law more directly.

In 'Human Rights and Environmental Protection in India: The Judicial Journey from Public Interest Litigation to the National Green Tribunal', Gill explores the fractious pressures between socio-economic development and environmental protection in an analysis of the role of the Indian judiciary in developing a jurisprudence responsive to both human need and environmental degradation.

The Indian context, Gill suggests, presents a paradox produced by the 'convergence of the right to environment and the right to development'. India's vast population - the sheer pressure of human numbers - along with rampant poverty, inflation and corruption - present particularly pressing challenges in response to which India embarked on a "new path of economic growth'. This has not, thus far, produced the collective benefits that might be aspired to, but has, instead, led to a widening gap between the rich and poor in India. Meanwhile, the growth agenda also frequently conflicts with human rights values and with the protection of the environment.

Gill's chapter addresses this paradox, and sets out to trace 'the successes and failures' of public interest litigation 'as a legal procedure to ... promote economic activity and simultaneously to maintain the 
environment', culminating in an analysis of the National Green Tribunal. The example of India presents a fascinating and salutary example of re-inventing the legal: in particular, as Gill's analysis establishes, the Indian judiciary have responded to poor regulatory responses to environmental degradation by forging 'innovative and creative [modes for the protection of] ecology and the environment'. Significantly, Indian public interest litigation opens a 'broad-based, people-oriented approach that provides access to justice and has become a "wheel of transformation" for victims of environmental degradation'. However, weaknesses and shortcomings vexing the public interest litigation procedures meant that further innovation and change were required. The Indian judiciary, again, rose to the challenge, delivering three judgments at the constitutional level that placed normative pressure on the Indian government to respond. Eventually, the trajectory of development culminated in the passing of the National Green Tribunal Act, in June 2010.

The Indian National Green Tribunal is an impressive model for future re-configurations of legal process, revealing a sensitive juridical response to environmental complexity. The decision makers on the Tribunal hold expert interdisciplinary qualifications, and 'judicial and scientific bench members act as joint decision makers of equal standing'. Here, arguably, are traces of a juridical strategy reflecting ample space for a critical environmental law theorisation - responsive, perhaps, to the quintessential openness of environmental law that PhilippopoulosMihalopoulos's chapter introduces.

The interweaving of the right to life and to a healthy environment in the Indian constitutional jurisprudence, likewise, emphasises the materiality and the vulnerability so central to questions of human and environmental justice. As is the case all over the world, in India the most pressurised points of convergence between interests occurs in conflict between the baseline, material, corporeal and situated needs of the 'poor' - in this case - the 'tribal poor' - and the 'powerful rich'. In response to this highly uneven dichotomy - so representative of wider patterns of the contemporary juridical order - the Indian judiciary offer a rights-sensitive response. Gill suggests that the National Green Tribunal is "laudable as its judgments recognize that "development" is the essence of any pragmatic and progressive society based upon a "balancing act" of not only supporting economic benefits but also encompassing the guarantee of protecting the environment and the fundamental human rights of the poor'.

Placing the rights and interests of the most marginalised members of society in a direct and intimate proximity to environmental concerns 
reflects, arguably, a critically attuned judicial response to climate injustice and to other recognisable patterns of oppression that bring nondominant humans, animals and ecosystems into an intimate proximity within the titled order of neoliberal capitalism. It is no surprise, then, that the National Green Tribunal's efforts are being 'hampered by' the Indian government's economic policies in the pursuit of 'unbridled growth':

Increasing political pressure is being exerted to promote economic development via public and private investment at the cost of the environment. The government is planning to amend the forest laws to increase economic activities in states, which hold some of India's most productive forests and also the majority of the tribal population. The government also seeks to dilute the Forest Rights Act that requires the consent of the local tribal population concerning change of use of forest land particularly mining for minerals ... [and by various means] excluding project-affected tribal people from the final decision-making process ... It is hoped that the [National Green Tribunal] will hold fast to its basic and established jurisprudence in the face of these new economic policies.

Human rights are often attacked for their individualism as well as for the disconnections evident between categories of rights. Evadne Grant, in 'Re-imagining Adjudication: Human Rights Courts and the Environment' examines this critique, conducting a review of the approaches of three regional human rights courts to reveal an iterative interpretive construction of an expanding relationship between human rights and the environment. Arguably, the central theme of Grant's account circles around the relatively prosaic, but powerful, generation of new sets of interconnections - between rights and rights, between rights and communities, and between rights, communities and environment.

Grant concedes the force in critical readings of the individualism and disconnectedness of human rights. She broadly accepts the fact that human rights approaches to environmental protection face important conceptual and procedural constraints, but argues that a close analysis of the developing jurisprudence of the various regional courts and related human rights institutions (in this case in the European, Inter-American and African regional systems) shows promising signs of an expanding jurisprudence pointing in another direction. There is nothing inherent in human rights law, her analysis suggests, that means that human rights reasoning cannot embrace group and community interests extending important and meaningful protection to the environmental contexts in which human well-being - whether individual or collective - is unavoidably situated. 
Grant's analysis suggests that notwithstanding manifold institutional and textual constraints, the jurisprudence of the regional courts reveals a quietly burgeoning potential for change effected through skilful interpretive extensions of traditional rights-based reasoning. Not only are courts connecting substantive human rights with each other in new ways, implying important community-dimensions of their meaning, but there is, in particular, a relatively un-trumpeted revolution being enacted by the quiet, constrained radicalism of procedural environmental rights. Grant's analysis suggests that despite their somewhat technical surface, procedural environmental rights are an increasingly important locus of immensely valuable modes of community inclusion. Such rights, she suggests, clearly recognise that environmental hazards affect whole communities. Despite varying modes of implementation across the three regional human rights systems, and despite the fact that procedural rights might lend themselves to State avoidance of more substantive standards, the quiet revolution enacted by the interpretation of procedural rights richly suggests the innovative, value-led determination of the regional courts to extend meaningful environmental protection to human beings and communities.

In Grant's analysis perhaps the most promising development concerns the increasing level of normative interweaving visible in the increasing tendency of judges to reach across jurisdictional boundaries to draw inspiration from the jurisprudence of other regions and even from national constitutional orders. Indeed, such promising judicial crosspollinations seem to have the effect of drawing the various international and regional treaties into ever more intimate conversational proximity with national constitutional provisions - suggesting a degree of normative convergence locating human rights within broader, ecological contexts (ecologies both 'natural' and juridical).

Ultimately, Grant concludes, while many might argue for a radical sweeping aside of existing paradigms, the incrementalism of the quiet revolution of judicial approaches points the way towards a new paradigm already being tested and implemented. Importantly, the normative foundations for this development are inherent to human rights law. Grant argues that from this perspective, while criticism of human rights individualism and disconnection is important, it may overlook the more prosaic realities of an environmental human rights law whose successful emergence is marked precisely by its lack of a radical break with the status quo - and which is, by implication at least, the more effective for that. 


\section{PART 3: ACTIVISM AND PRAXIS}

Kate Donald's chapter 'Human Rights Practice: A Means to Environmental Ends?' implicitly addresses doubts concerning whether or not human rights practice in its current dominant forms can tackle the challenge of climate change and global environmental degradation. Donald argues that while the symbiosis between human rights and the environment is increasingly well established, human rights - for all their potential to contribute in concrete ways to moving an environmentally responsible agenda forward - have not thus far realised it. Whether they can or not still remains a relatively open question. In fact, Donald's analysis implies that human rights cannot assist in the search for environmental justice or fuller environmental accountability unless we adopt and pursue 'radical or hybrid approaches, with a view to articulating a strategy for activism and praxis that can capture the real and lived inter-connectedness of human rights enjoyment and environmental factors more meaningfully'.

In order to defend this thesis, Donald addresses three dominant existing approaches to human rights praxis - each of which reflects different understandings of the relationship between human rights and the environment. First, there is the strategy of lobbying for the adoption and institutionalisation of new environmental human rights. Secondly, there is the strategy of deploying existing human rights mechanisms to tackle environmental harms. Thirdly, there is the strategy of taking a human rights-based approach to environmental practice.

Donald concludes that the first strategy, while it holds out hope for activists, is unlikely to offer much in more substantive, juridical terms due to a range of institutional and political weaknesses in the dominant formulation of human rights. There are, moreover, she suggests, fundamental questions as yet unanswered by the strategy - particularly concerning its location in the unproductive dichotomisation between anthropological and ecological approaches. The current challenges reflect the need to embrace both the environmental and human costs of failing to respect the Earth system - but Donald remains doubtful that even a human rights treaty with universal applicability could overcome the concerns represented by the intractable questions presented by the controversies surrounding the relationship between human rights and the environment. The second strategy - of using existing human rights mechanisms (courts, UN treaty bodies, special procedures) to protect the environment - Donald considers to be "worthwhile ... in certain cases [but to have] limited capacity and reach' - noting that while environmental issues are often 
united with social and economic rights, they suffer from the same weaknesses concerning their perceived justiciability status. This is a key weakness, arguably, in strategies seeking to deploy existing socioeconomic human rights entitlements as an avenue for the protection of environmental rights. The third strategy, the deployment of a 'human rights-based approach' to environmental matters, is more promising - but particularly 'when applied to activism and action on the ground with a sensitivity to context'.

This third strategy arguably reflects a socio-legal critical approach one moving into forms of eco-humanitarian grassroots organisation and engagement and implying the energies emerging from responses to localised, environmental injustice, and also one highly connected, we would suggest, to Code's argument for advocacy conducted in the full light of detailed, situated analysis and sensitive to situated subjectivities.

A rights-based approach, in Donald's analysis, and understood in the way she defines it, has the potential to be subtle, flexible and responsive to structural and multi-faceted causes of rights violations and lack of rights enjoyment. Donald gives specific core content to the third broad strategy: her emphasis is upon accountability; equality and nondiscrimination; participation and empowerment. Each of these terms, she notes, has a particular meaning in human rights contexts. These meanings, it should be noted, directly address the problem of marginalised subjectivities - and implicitly critique the dominant hegemonic subject because they imply a notion of equality given substantive content by gender-sensitivity, non-discrimination and an implication of affirmative action. Thus, while Donald emphasises the significant potential for rights-based approaches to 'address and question structural and systemic causes of disempowerment and vulnerability to (for example) poverty or environmental harm', it is of note that this relies upon stepping back from law's institutional provision to operationalise more fluid approaches and adaptive, ground-level strategies. This less predictable way of working holds out hope of facilitating a more reflexive, liberated and effective form of human-rights-based practice.

Such approaches, however, need to keep a clear sense of the complexity of human rights as semantic, semiotic and juridical tools. It seems that what such rights-based approaches have the greatest potential to do is to place the battle for human rights meanings at a more localised, contextualised level characterised by a certain productive contingency and flexibility of response. This is to be welcomed; yet there remains a need for explicit caution concerning the assumptions to be held about human rights - a view evidently shared by Donald, who reserves her greatest enthusiasm, in the end, for a fourth, alternative " principled strategy" for 
the embedding of the interdependence of human rights and the environment in human rights practice, based on a realistic interpretation of the strengths and weaknesses of human rights in its various shifting and contested forms'. Donald's is, then, a decidedly non-monolithic reading of human rights - one placing their haunting ambiguities firmly in view and entirely open to a creative blend of the strengths of various strategies - while aware of their weaknesses - and blurring the boundaries, potentially, between rights-based activisms and other social movement claims for social and climate justice.

Indeed, it is as claims that human rights may do their deepest work. For Donald, 'claims-making is a distinctive part of human rights practice and has intrinsic worth and radical potential'. Claims-making on this view forms a kind of transformative advocacy close to the advocacy that Code champions in her chapter. This is the kind of claim-making, narrative-telling, argument-making intervention that produces shifts in consciousness precisely by problematising what is taken for knowledge in the fraught environmental justice context. This makes a distinct gesture away from law to the discursive power of human rights as an idea animating activist resistance. This is a messy, energetic conception of rights-claims that allows us - as Baxi puts it (cited by Donald) - to '[construct] some new alternate futures beyond the new paradigm of trade-related, market friendly and environmentally hostile human rights'. Indeed, the struggle for environmental justice, for Donald, also 'has the potential to contribute to a much-needed task: the renewal and reconstruction of human rights in a more radical form'. Thus, in the way that human rights, for Coyle, point to a bond-conserving sensibility capable of addressing the separative fantasies of the modern liberal consumer state and directly assist environmental law in its 'conserving' role, for Donald, human rights themselves become transformed by social movement energies directed by the centrality of the environment to questions of justice. Against a background in which, despite the growing importance of the environment in human rights discourse, human rights are increasingly marginalised at the institutional level within international environmental fora, Donald argues that 'those who are concerned with environmental protection and with human flourishing in a healthy environment should encourage, use or welcome a "principled strategic" use of human rights, based on an analysis of what can best realise inevitably contextual visions of justice, dignity and flourishing'. In particular, this re-energisation of human rights becomes all the more urgent in the context of the emergence of capitalism's reinvention of ecological justice in the form of the green economy - a concept 'lacking even a human 
focus'. Human rights practice, by contrast, holds out hope for a 'principled yet strategic, profoundly context-dependent' approach that accepts shifting power relations as core to its analysis. Key to this - at all times - are the energies of social movement actors on the ground.

Tom Kerns would undoubtedly wholeheartedly endorse the importance of this kind of ground-level claim-energy. His careful analysis, in 'Schopenhauer's Mitleid, Environmental Outrage and Human Rights', drives directly at the activist's concern with the energies emerging from the lived-experience of violation, of environmental and human degradation, and the 'outrage' energising human rights in their most liberatory mode. Kerns's analysis is intrinsically context-responsive, located and situated. It suggests not only the ultimate ontological unity between humans and environment but the productive, visceral intimacy between outrage, speech and the search for eco-humane justice.

Kerns argues that suffering that results from exposure to environmental violations evokes a sense of moral outrage - and that this outrage can be grounded in Schopenhauer's important philosophical work on compassion. Human rights, argues Kerns, function as an important source and form of validation for outrage. Importantly, Kerns also argues that Schopenhauer's account leads towards an explanatory grounding for the 'long-recognized importance of personal narratives in human rights work'. In short, human rights confirm and publicly validate what compassion first intuits - an insight leading to three practical implications for environmental activism: the central importance of personal narratives detailing the direct impacts that environmental assaults have caused'; 'the practical value of formal, detailed human rights assessment reports specified to a given situation'; and 'the value of community-led public inquiries, such as the 2006 People's Inquiry in New Zealand and the 2011 Permanent People's Tribunal in India'.

Kerns's central philosophical claim is that Schopenhauer's ethic of compassion, his Mitleids-Moral, provides a better account of the human experience of moral outrage than do the other systems of ethical thought (Aristotelian, Kantian, Millian) often called upon in human rights philosophy. Kerns's analysis drives at the visceral sense of empathy lying in the radical, critical foundations of human rights when they first emerge and before they are captured, as it were, by human rights law:

As Lynn Hunt says in Inventing Human Rights: A History, 'we are most certain that a human right is at issue when we feel horrified by its violation'. When we see or hear of such horrible injustices we are often seized with shock and outrage and blurt out, if only to ourselves: 'How awful! How could anyone do such a thing?' 
This is the response of compassion - a compassion that for Schopenhauer (and Kerns) is 'participation in' another's suffering.

The mystery of this compassion is explained by an empathic openness born of the ontological reality of our fundamental unity of being: 'All these multiple beings in the world of phenomena, i.e., all the temporalspatial multiplicities of our experience, are, for Schopenhauer, phenomenal expressions of the same underlying fundamental reality, Der Wille': We are all different manifestations of the same underlying reality. It is this ontological fact that provides the metaphysical explanation of our exposure to the sufferings of another.

This explanation reticulates with the idea that we can feel the sufferings of others resonate in our own embodied vulnerable being. For Schopenhauer, as Kerns makes clear, our fundamental unity with all things means that we experience the sufferings of others as if they were our own. This fundamental insistence upon a kind of empathic corporeal communication growing from ontological commonality is, in a sense, a rather different way of driving at the vulnerability central to the structure of existence. It intimates, without conforming with, the sense of the vulnerable space of the middle that Philippopoulos-Mihalopoulos emphasises in his contribution to this collection, suggestively hinting at the radical 'suchness' of what exists as being a fundamentally vulnerable, open field of dynamic movement, shifts and interactions between 'actants' (to use Philippopoulos-Mihalopoulos's term).

Kerns suggests that Schopenhauer's ethic of compassion captures something of the personal, existential sense of outrage at unnecessary suffering. He argues that the international human rights tradition 'provides another level of validation for that sense of outrage and the felt necessity of acting on it'. Human rights norms take the hot energy of compassion and channel it through public structures - enabling recognition of what begins as a most personally felt violation. Human rights, in this sense, appear in Kerns's vision to function as a mode of enunciation or articulation - as a channel for engagement concerning environmental (and human) violation. From this, for Kerns, certain insights follow for environmental justice activism. He suggests that:

If the central claims of this paper have validity, and if Lynn Hunt's historical account of the role of empathy in the genesis of rights discourse is correct and she is right to argue that 'rights are best defended in the end by the feelings, convictions, and actions of multitudes of individuals, who demand responses that accord with their inner sense of outrage', then at least three practical implications follow for environmental activism. 
First, telling the story: Kerns emphasises the power of the meaningful personal account of direct impacts and the importance of collecting and documenting these narratives of violation. Secondly, claiming moral authority:

Providing activists with well-researched Human Rights Impact Assessments of their specific situation can help clarify the moral dimensions and values at stake as well as identifying potential pressure points. Foregrounding and documenting human rights standards that apply in that particular situation can publicly validate the felt sense of injustice and legitimise the outrage experienced by those whose lives have been negatively impacted.

Thirdly, and finally, exercising moral power: Here Kerns emphasises the potency of community-led public inquiries - pointing to successful examples of community-initiated people's tribunals, which have the advantage of being able to be truly inclusive. These are, in a sense, modes of hearing pain and outrage speak truth to power - a very practical endorsement of Code's powerful advocacy-based argument for ensuring epistemic openness in the face of tactical diminutions of the 'authority' to know, and of Donald's arguments concerning the role of flexible, rights-based approaches. Kerns's emphasis upon Mitleid also resonates with a concern for the most marginalised and socio-economically disempowered communities.

The intransigent tensions between situated, embodied, eco-material needs, socio-economically problematic imperatives of neoliberal economic expansionism, activist aspirations and the internal contradictions of rights as paradoxical forms of complicity and resistance adds to the general sense, communicated in the contributions to this collection thus far, of profound urgency of a shared, albeit diversely constructed, search for a renewed responsiveness to contemporary crises. The final two chapters in this collection offer thoughts towards a 'multi-level reformulation'. The contributions in this final section share much in common with some of the earlier contributions, but overtly trace the contours of future-facing developments intimating the shapes of new juridical imaginaries explicitly responsive to socio-ecological complexity and to the need for new modes of responsiveness.

\section{PART 4: MULTILEVEL REFORMULATIONS}

In 'Reimagining Ecological Governance Through a Rediscovery of the Commons', David Bollier and Burns Weston draw upon their earlier work to 'argue that the Commons paradigm, especially when guided by 
human rights law and policy, can help us imagine and implement a new vision of provisioning and democratic governance'. Importantly, Bollier and Weston do not 'propose an abrupt, revolutionary change, but one that can feasibly evolve within the fragile, deteriorating edifice of existing institutions'. For Bollier and Weston, the unique strength of the commons, both as a discourse and as a 'set of ethical social practices' is its combination of a coherent critique of the status quo, its embrace of legal principles with powerful, imaginative implications for the design of proactive, change-making strategies and - last but certainly not least - a 'transnational movement of commoners who are co-creating innovative new provisioning and governance systems that work'. Importantly, especially given the multiply-manifested crises attending the 21 st-century situation, the commons has a 'secret potency' that: 'can help to disrupt the State/Market's pathological dependence on economic growth and begin to set enforceable limits on the overexploitation and abuse of Earth's natural systems ("the tragedy of the market")'.

Bollier and Weston make explicit the fact that a re-imagined (and re-experienced) sense of humanity lies at the heart of the power of the commons. The commons is an incontrovertibly social phenomenon that refutes the assumption that human beings are self-centred, valuemaximising, rationalistic individuals. The commons, Bollier and Weston emphasise, 'argues that human beings [also] have many more complex propensities - for cooperation, creative initiative, sacrifice for collective interests, idealism, etc'. Commons are, archetypally, the 'intermediate communities' that Coyle writes of. They reflect, arguably, the interwoven self lying at the heart of an ecological epistemological project - as well as the central importance of situatedness in the generation of normative ethical impulses. In a sense, it is precisely their sensitivity to a groundlevel politics of location that lends commons-based governance its incredible flexibility and reflexive openness: the greatest power of the commons lies precisely in its 'highly particularistic lived realities'.

The commons framework, as Bollier and Weston make clear, draws upon energetic commons-based scholarship, and upon a 'global movement of commoners that began to emerge in the late 1990s and early 2000s, much of it fuelled by the World Wide Web and free/open source software'. The sheer variety of commons is almost dizzying. At local, national and transnational levels commons proliferate in a kaleidoscopic range of resources. Bollier and Weston name: 'subsistence agriculture, stewardship of water, the re-localisation of agriculture and other production, open access scholarly publishing, new forms of "open source design and manufacturing" for cars, furniture, farm equipment, policies for a "shareable city", scientific data sharing, "collaborative consumption", 
cooperatives and alternative currencies, among many others'. The focus is on building, ground up, workable modes of 'fair, inclusive and sustainable ways' of 'managing and preserving shared resources'.

For Bollier and Weston, the felt-experience or sense of vulnerability is a powerful explanation for the growing appeal of commons-based self-organisation. It is, in a direct sense, a profoundly human response to the dehumanising impersonal injustice of the 'State/Market' duopoly. Referring to their book, Green Governance, Bollier and Weston argue for a 'commons imaginary' that 'calls for innovative uses of State and human rights law and policy to facilitate the formation and maintenance of ecological commons'. In short, they propose that 'modern law should recognise the age-old paradigm of the Commons and provide affirmative recognition and support for the right to common'.

This call, in a sense, demands the bringing forth of a fully ecological epistemic and ethical framework in law and governance structures - a space of creation for a far more open socio-juridical ontology to emerge in tangible, interwoven community-based praxis. The Commons paradigm has much in common - therefore - with other contributions in this collection. It also expands the notion of law itself. Bollier and Weston specifically call for a notion of 'vernacular law', 'vernacular' being a word that (here they quote Illich) "implies "rootedness" and "abode" and derives from the Latin word Vernaculum that described "sustenance derived from reciprocity patterns embedded in every aspect of life, as distinguished from sustenance that comes from exchange or from vertical distribution"”.

For Bollier and Weston, human rights can play a pivotal role in the development of the new paradigm, ensuring the juridical space for this complexity-sensitive mode of grassroots adaptive self-governance to flourish through a 'human right to green governance'. Their contribution openly celebrates the power of grassroots-driven approaches, validated by complexity science demonstrating that 'some of the most robust, stable forms of governance are distributed, self-organised and collaborative'.

It is not too great a stretch to see how this vision returns us to considerations of the dynamism, complexity, vulnerability and energies of an open ontology and to the radical epistemic humility demanded by new philosophical imaginaries drawn from the new materialist visions and critical theories informing, in particular, the work of PhilippopoulosMihalopoulos and Code in this edition.

Anna Grear's contribution, 'Towards New Legal Futures? In Search of Renewing Foundations' draws from similar inspirations - turning a processual ontology towards an epistemology, ethics and re-imagined set of legal process patterns entirely consistent with the opening chapters of 
this collection. Grear suggests that the 'animating purpose' of her chapter is to 'reflect upon insights yielded by a lively confluence between critical environmental law scholarship and new posthuman materialist ontologies (from which critical environmental law itself draws)', placing these in 'direct engagement with a search for a renewing socio-juridical imaginary in which the relationship between human rights and the environment might be reimagined'.

Grear contextualises the concerns of her chapter within the emergence of the Anthropocene, reading the Anthropocene construction of a new universal humanity critically, before exploring some broad directions for new human and environmental foundations for law and legal processes. Grear insists that for all the potency of speaking of a common vulnerability in the face of climate change (the level of threat co-situates 'us' "with countless "other species" and living systems'), the contemporary Anthropocene crisis is characterised by conditions of 'common and uneven precarity'. What then, is law's response? Grear is clear that the current legal paradigms of human rights and the environment have signally failed to respond adequately. The 'track record' she argues is 'lamentable. International legal regulation and governance regimes exhibit profound limitations impeding genuinely transformative possibilities'. She suggests that:

If climate precarity - as Chakrabarty argues - 'flashes up' the need for a construct through which to imagine new ways of being and eco-wise future histories, then it will be essential to replace the subject-object relations at the foundation of climate crisis and the unjust patterns of the neoliberal international legal order alike, introducing new, inclusive eco-subjectivities including new eco-juridical subjectivities.

Fortunately, Grear suggests, the broad outlines of such future-facing possibilities exist. Turning to new materialist philosophy, she draws upon the work of Merleau-Ponty, Barad, Haraway, PhilippopoulosMihalopoulos, and also of Code, to suggest that a dynamic, new materialist processual ontology is already on offer, one with rich implications for new forms of inter- and intra-species justice - and drawing on the work of Pieraccini and Philippopoulos-Mihalopoulos - able to produce new legal normativities arising from the interactions between non-human animals, receptive humans and living contexts. Additionally, Grear argues, Code's ecological epistemology points the way towards a new ethical sensitivity to the question of situated positionality, making the question of situatedness itself intrinsic to ethical encounter. All of this hinges, Grear's analysis implies, on a rejection of the fundamental 
subject-object relations underpinning the present system and its construction of legal subjectivity and an embrace of new, dynamic and open interwoven realities in which subject and object emerge as a form of presencing contingently 'arrested' for particular purposes.

Finally, Grear turns her analysis towards legal process values, suggesting that not only might law move towards a range of less formal modes of hearing - towards a wider range of situated, complexity-sensitive epistemic fora - but that traditional legal process values themselves might be re-imagined. Thus audi alteram partem and nemo judex in sua causa could be reconstituted:

[t]he central point is that legal processes can become more sensitive to the multiple implications of the materio-semiotic knottings of Haraway's rich invitation to 'meet', as it were, between species of all kinds ... Science could inform this process by directing a whole range of non-human 'inputs' into ... an open juridical epistemology, producing a more eco-inclusive notion of audi alteram partem responsive to measurements of ecological integrity, ${ }_{1}$ but resisting assumptions concerning the completeness or epistemic dominance of scientific knowledge itself. Such inputs might produce a reconceived 'alteram' - the 'alter' (or 'other') no longer being merely confined to a human or other existing legal protagonist (a company, a local authority and so forth), but being understood to embrace multiple life-forms and systems seen as co-participants in the formation of normative outcomes.

Grear's conclusion is apt as a conclusion for this collection:

A new juridical imaginary is possible - and vital to build. The ... foundations are being laid ... Law and legal theory, by responding to ... new, passionate visions of an interwoven world, would follow ... a deeply ethical impulse. The time has come. New future histories summon the legal ... imagination and potential new interpretations and modes of legal [and other modes of response] offer meaningful, practical ways of responding to the call.

1 L Westra, K Bosselmann and R Westra, Reconciling Human Existence with Ecological Integrity: Science, Ethics, Economics and Law (Earthscan 2008). 